\section{Cerebral sparganosis}

\section{Esparganosis cerebral}

\section{Dear Editor:}

The recent case report by Caballero, et al. on "Cerebral sparganosis" is very interesting ${ }^{1}$. Caballero et al. noted that the case was the second report in Cuba. I would like to share the experience on this infection from Thailand, an endemic area of sparganosis ${ }^{2-5}$. Focusing on the diagnosis of sparganosis, the use of brain imaging can provide the primary presumptive diagnosis ${ }^{2-5}$. The infection should be listed in the differential diagnosis of any patients presenting with unexplained brain lesions with or without history of living or visiting to endemic area ${ }^{2-5}$. The use of aspiration, as in the present case ${ }^{1}$, is not routinely done and not suggested. The use of antiparasitic drug for treatment is firstly recommended and the surgical removal should be done only in case with indication for neurosurgery (such as compression $)^{2-5}$.

\section{Estimado Editor:}

La reciente comunicación de Caballero, et al., en "Esparganosis cerebral" es muy interesante'. Caballero y cols., señalan que el caso fue el segundo reporte en Cuba. Me gustaría compartir la experiencia de esta infección en Tailandia, una zona endémica de esparganosis ${ }^{2-5}$. Centrándose en el diagnóstico de esparganosis, el uso de imágenes cerebrales puede proporcionar el diagnóstico presuntivo primario $^{2-5}$. Esta infección debe estar en el diagnóstico diferencial de cualquier paciente que presenta lesiones cerebrales inexplicables, con o sin antecedentes de vivir o visitar zonas endémicas ${ }^{2-5}$. El uso de la aspiración, como en el presente caso ${ }^{1}$, no se realiza de forma rutinaria y no es sugerida. En primer lugar, se recomienda tratamiento antiparasitario médico y la extirpación quirúrgica debe realizarse sólo en caso de alguna indicación neuroquirúrgica (tales como, compresión) $)^{2-5}$.

\section{References/Referencias bibliográficas}

1.- Caballero J, Morales L, García D, Alarcón I, Torres A, Sáez G. Stereotactic aspiration of Spirometra mansonides larvae. Rev Chilena Infectol 2015; 32: 453-6.

2.- Wiwanitkit V. Cerebral sparganosis. Clinics (Sao Paulo, Brazil). 2012; 67: 1347.

3.- Wiwanitkit S, Wiwanitkit V. Follow-Up MR imaging for cerebral sparganosis. Am J Neuroradiol 2012; 33: E131.

4.- Wiwanitkit V. Cerebral sparganosis. Br J Radiol 2010; 83: 807.

5.- Wiwanitkit V. A review of human sparganosis in Thailand. Int J Infect Dis 2005; 9: 312-6.

Viroj Wiwanitkit

Hainan Medical University, China Surin Rajabhat University, Thailand

Correspondencia a: wviroj@yahoo.com 